\title{
Е.И. Тулякова
}

\author{
КОММУНИКАТИВНЫЕ СТРАТЕГИИ ИЗДАТЕЛЯ \\ В ЖУРНАЛЕ «ДЛЯ ДЕТСКОГО И ЮНОШЕСКОГО \\ ЧТЕНИЯ» В. МАЙКОВА «ПОДСНЕЖНИК» (1858-1862)
}

\begin{abstract}
В статье рассматриваются две издательские коммуникативные стратегии, используемые В.Н. Майковым в детском журнале Подснежник» и позволяюшие назвать его журналом «нового типа». Первая - прагматическая, реализуемая через издательский паратекст журнала и связанная с точкой зрения взрослого адресата. Вторая - художественная, направленная на читателя-ребенка, рассчитанная на его восхождение под руководством взрослого наставника от читателя «наивного» к читателю рецептивному посредством чтения и восприятия художественных произведений в журнальном метатексте.

Ключевые слова: детский журнал, коммуникативные стратегии, читатель, метатекст.
\end{abstract}

Q журналистике 1850-1860-е гг. называют временем становления профессионального детского журнала. Развиваясь вслед за журналом взрослым, детский журнал впитывал в себя продуктивные издательские стратегии, тем самым пытался вписаться в общелитературный процесс и занять там свое особое место. Среди достижений детской журналистики этого периода авторитетный современный исследователь в данной области Л.Н. Колесова выделяет следующие: увеличение количества детских журналов (в XVIII в. их было 1-2, в первой половине XIX в. - 32, во второй половине - 70), дифференциация по возрастам, специализация по тематике, интересам, общественно-политической, педагогической, эстетической ориентации [1. С. 61-62]. Начинают формироваться типичные черты детского журнала как вида издания: периодичность, рубрицированность, единообразие оформления, привлекательность для читателя, многосубъектность, установка на общение с читателем и пр. Если взрослый журнал «принял близкий к современному вид и стал выполнять современные функции» в 1820-1830-е гг. [2. С. 581], то детский журнал - в 1860-е гг.

Журналом «нового типа» (М. Костюхина), положившим начало профессиональному детскому периодическому изданию, стал жур- 
нал «Подснежник» (1858-1862). Его основателем и редакторомиздателем стал Владимир Николаевич Майков (1826-1885), один из четырех сыновей известного живописца Николая Аполлоновича Майкова (1794-1873). Фигура издателя во многом определила и место, и концепцию, и судьбу журнала. Владимир Николаевич Майков, человек образованный (в 1850 г. окончил Петербургский университет), хорошо эрудированный (прекрасно знал английский язык, занимался переводами), трудолюбивый (занятия литературой совмещал со службой «нелитературного характера»), хорошо известный в литературной среде своего времени благодаря братьям (Аполлон Николаевич - поэт, Валериан Николаевич - литературный критик, Леонид Николаевич - кандидат филологических наук) и собственному дарованию (в его переводе в журналах «Современник», «Библиотека для чтения», «Отечественные записки» публиковались произведения Ч. Диккенса, В. Ирвинга, В. Скотта, Г. Бичер-Стоу, Г. Филдинга), проявил особый интерес и к издательскому делу. В 1856-1857 гг. он помогал А.В. Дружинину, редактору «Библиотеки для чтения». Это сотрудничество, очевидно, дало Владимиру Майкову тот опыт организации журнального дела, который позволил ему создать свой журнал, имеющий собственное направление, определенное и литературной позицией (увлечение европейской литературой), и личными интересами своего создателя (чувственные воспоминания собственного детства, гармоничная, творческая и счастливая семья, а также искренняя любовь к свой семье, жене и детям) ${ }^{1}$.

Из коммерчески успешного взрослого журнала «Библиотека для чтения» Майков заимствует, прежде всего, прагматические коммуникативные стратегии издателя-книгопродавца А.Ф. Смирдина. Если детские журналы первой половины XIX в. имели ограниченную аудиторию (были ориентированы на детей высшего сословия, или учащихся определенных заведений), сферу распространения, высокую цену и потому «не выживали» долго, то В. Майков попытался расширить читательскую аудиторию, о чем говорят и тематика публикуемых произведений (появляются непривычные для детской ли-

${ }^{1}$ Фактический материал о жизни и деятельности В.Н. Майкова полно представлен в работе: Володина Н.В. Майковы; отв ред. В.А. Котельников. СПб.: Наука, 2003. 340 с. (Преданья русского семейства). Приведен нами с опорой на данное издание [3. С. 163-164]. 
тературы, но актуальные темы социального неравенства, крестьянского быта, тяжелого положения детей и пр.), и новый тип героя (крестьянские дети, бедные дети); сделать приемлемой цену (подписка на 12 книг в год стоила 6 р. Ср.: книги, которые приводятся в рекламных отделах журнала, стоят в среднем 1 р. 50 к., дороже журнала в 3 раза при том же объеме); расширить территорию распространения журнала, включая провинцию, предложить различные варианты подписки и др.

Прагматический подход определил издательский паратекст журнального ансамбля. Как и во взрослом журнале, он ориентирован на взрослого первочитателя-покупателя, реальную, биографическую личность.

Издательский паратекст, представляющий совокупность околотекстовых компонентов, выступая как самостоятельный вторичный (или периферийный) текст, имеет коммуникативно-прагматическое содержание и реализует совокупность функций: коммуникативную, рекламную, эстетическую. Обладая таким потенциалом, он репрезентирует первичные тексты издания и дает о нем самое первое представление, формируя читательские ожидания, определяя потребность в издании. В детском журнале «Подснежник» издательский паратекст выстраивается таким образом, чтобы убедить покупателя, взрослого наставника, в первую очередь в авторитетности журнала и полезности его приобретения для юного читателя.

Особенно актуальным это становилось в период идеологической борьбы за статус и место детской литературы и детской книги. Благодаря активному участию взрослых писателей, критиков, педагогов, общественных деятелей, издателей к 1860-м гг. было сформировано более или менее единое мнение: издание для детей должно быть одобрено цензурой, педагогикой, критикой; особым образом оформлено: сопровождаться иллюстрациями, прикладным материалом. По сути, все это и было критериями «хорошей» и «плохой» детской книги, в том числе и для ее покупателей.

Майков рассчитывал на широкое распространение журнала «Подснежник» и ему важно было убедить потенциального покупателя, что его детский журнал удовлетворяет основным требованиям к детскому изданию.

Для этого, во-первых, в журнал вводится официальный дискурс: на обороте титульного листа каждого номера издатель размещает 
цензурное дозволение с указанием даты и имени цензора, а также одобрение Министерства народного просвещения на самом титульном листе.

Во-вторых, значительное место уделяется педагогическим материалам. Так, в № 2 (февраль) за 1860 г. на открывающей полосе (после раздела «Содержание») издатель помещает рекомендательное распоряжение господина министра народного просвещения об «употреблении журнала «Подснежник» в учебных заведениях министерства народного просвещения; в рекламном отделе к отдельным номерам (№ 2. Февраль. 1858; № 3. Март. 1860 и др.) Майков печатает статью «Об издании «Журнала для воспитания», которая занимает шесть полос издания и напрямую обращена ко взрослому читателю: «...прямое предназначенье нашего издания сделаться необходимым и вполне полезным руководством для родителей, воспитателей и преподавателей» [4. 1858. № 2. С. 172].

Педагогически-методический характер носят и статьи от издателя, регулярно помещаемые в разные номера журнала. Например, в № 2 (февраль) за 1859 г. взрослому покупателю разъясняется назначение журнала «Подснежник», который должен стать «непрерывным, беспрестанно наполняющимся и разнообразным источником чтения, которое должно служить правильным, периодическим дополнением и развитием преподаваемых детям и юношам уроков по всем частям знаний» (выделено мною. - E.T.), здесь же приводится его программа в совокупности образовательных, развивающих, воспитательных, эстетических задач. В № 1 (январь) за 1861 г. издатель формулирует методические принципы изучения истории: «соответствие современному состоянию исторической науки, (исторические факты. - E.T.) обнимали бы подробности предмета, изображались с возможною выпуклостью личности исторических деятелей, передавали происшествия с драматической занимательностию и представляли бы дух времени и колорит местности» [4. 1861. № 1].

Педагогический дискурс определяет цель и характер многих редакторских примечаний к статьям. Например, Майков объясняет связь исторического материала, помещаемого в журнал, с учебным курсом истории: «...а самый текст (должен. - E.T.) служить пополнением тех сведений, которые в учебники войти не могут, но без которых история мертва» [4. 1860. № 3. С. 86]; пытается донести до читателя свое видение преподавания истории: «...курс отечествен- 
ной истории приходится сокращать, ограничивая его указанием и объяснением только важнейших явлений народной жизни. Сообразно с этим, составляются программы преподавания и пишутся учебники, причем и те и другие неизбежно грешат или сухостью, происходящею от желания коснуться как можно большего числа фактов, или неполнотою, если имелось в виду оживить имена, числа и происшествия драматическим рассказом и историческою мыслию» [4. 1860. № 3. C. 84].

Заметим, что издатель в этих материалах апеллирует только к взрослому читателю, укорененному в повседневно-практической сфере. Прямой читатель журнала, ребенок, здесь является лишь объектом редакторских замечаний. Методические материалы журнала предполагают осведомленность покупателя в современных педагогических конвенциях и потому должны быть оценены им высоко.

В-третьих, потенциального покупателя необходимо было убедить в качестве публикуемых материалов, в первую очередь художественных. В.Н. Майков делает ставку на литературную компетентность взрослого покупателя.

Прежде всего, издатель заостряет внимание на авторском уровне в организации журнала. Определенным знаком для взрослого читателя должно было послужить имя самого издателя, как говорилось выше, известного в литературной и культурной среде общества. Не случайно свое имя Майков помещает на титульном листе каждого номера, выделяет его достаточно броским полужирным шрифтом.

Планомерно издатель работает над авторским составом своего журнала, о чем свидетельствует программная рубрика самого первого номера «Участвующие в журнале». Всю полосу выходного титульного листа занимает список авторов, где среди малоизвестных имен детских писателей, полиграфически выделяются имена известные как в детской (Е.Е. Барышов, В.И. Водовозов, А.А. Пчельникова, М.О. Ростовская и др.), так и во взрослой литературе (И.А. Гончаров, Г.П. Данилевский, Н.А. Майков, Н.А. Некрасов, А.В. Никитенко, И.И. Панаев, А.Ф.Писемский, Я.П. Полонский, И.С. Тургенев и др.).

Фамилии и инициалы авторов произведений Майков размещает и в содержании каждого номера (это выглядит значимым на фоне принятого безавторства детских журналов XVIII-XIX вв.). 
Акцентируется внимание к автору путем введения популярнопросветительских подстрочных примечаний. Например, в № 2 (февраль) за 1858 г. Майков помещает два стихотворения под заголовком «Из Саади» и дает достаточно развернутую биографическую справку о персидском писателе [4. 1858. № 2. С. 3-4]; в № 7 (июль) указывает на авторство рассказа «Лебеди»: «...этот рассказ взят из воспоминаний немецкого писателя Ламотт-Фуке, автора «Ундины», переведенной Жуковским [4. 1858. № 7. С. 19].

В отделе, посвященном рекламе книг, продаваемых в магазине В.А. Исакова, также выделяются (прописным начертанием) имена европейских и русских авторов, известных просвещенному читателю: Фенелон, Свифт, Бюффон и др. [4. 1858. № 5. С. I-V].

В номерах журнала встречаются рекламно-просветительские заметки редактора о выборе публикации того или иного автора. Так, в № 8 (август) за 1858 г. в статье «От редакции» подписчики уведомляются о подготовке для номеров «Подснежника» повестей для детей Натаниэля Готорна. Имя писателя здесь выделено крупным начертанием, издатель подчеркивает, что это знаменитый американский писатель и его произведения успешны в Америке и Европе, а потому «редакция надеется, что повести эти, исполненные юмора и глубокой нравственности, написанные изящным языком, будут иметь у нас такой же успех» [4. 1858. № 8. С. 148].

Примечательно, что ценность обещанных за подписку подарков от издательства, литературно-художественных изданий, издатель определяет именами их авторов (не случайно выделяет их жирным шрифтом). Например, подарок, обещанный в № 12 (декабрь) за 1858 г. ценен тем, что в него войдут отрывки из сочинений И. Тургенева, И. Гончарова, стихотворения А. Фета, Я. Полонского, А. Майкова.

Высокий художественный уровень публикуемых материалов подчеркивает и отбор хорошо известных, прежде всего в литературе взрослой, жанров и произведений. Майков отказывается от привычных для детского журнала жанров назидательной повести, басни, отдавая предпочтение привычным для взрослой публики стихотворению, рассказу, роману.

Наконец, в-четвертых, взрослому читателю, знакомому с книгоиздательской культурой своего времени, предстояло оценить, насколько внешне привлекателен детский журнал и удобно ли им 
пользоваться. Этим объясняется строгое, четко структурированное оформление «Подснежника».

Содержание вынесено в начало каждого номера, по виду оно полноохватное, часто аннотированное, позволяющее составить представление о наполнении журнала и уровне публикуемых материалов; в отдельных номерах имеется ретроспективное содержание номеров журналов за прошлые годы (например, оно подверстывается к № 3 за март 1860 г.). Структура каждого номера оформляется системой рубрик: каждое новое произведение верстается с новой полосы со спусковым заголовком.

Забота издателя о достойном оформлении журнала видится в подборе иллюстративного материала. Например, редакция уведомляет читателя, что ею «выписаны из Парижа для «Повестей, заимствованных из мифологии» Натаниэля Готорна... картинки известного французского рисовальщика Берталля» [4. 1859. № 1. С. 137], в программе к журналу издателем обещаны «картинки, чертежи, географические карты, планы, которые, прикладываются к статьям» [4. 1859. № 2. C. VI] и пр.

Таким образом, прагматическая коммуникативная стратегия реализуется через издательский паратекст журнала, который формируется как единый самостоятельный риторический текст, рассчитанный на точку зрения взрослого адресата, его литературную и педагогическую компетентность, интересы, покупательские возможности. Издательский паратекст дает возможность представить взрослого «читателя» журнала как образованного человека, искушенного читателя, знакомого с литературным и издательским процессом своего времени, озабоченного эстетическим и интеллектуальным воспитанием ребенка в русле современной ему педагогической и культурной традиции.

Иная коммуникативная стратегия выстраивается издателем по отношению к читателю-ребенку, ее можно назвать эстетической или художественной. Она реализуется в процессе прочтения и восприятия художественного произведения, а потому в ситуацию общения оказываются втянутыми все участники художественного диалога: автор, персонаж и читатель.

В рамках отдельного произведения между ними возникают свои межличностные связи. Коммуникативные стратегии художественного произведения раскрываются через авторскую этико-эстетическую 
позицию, воплощаются на разных уровнях поэтики и влияют на читателя. Их цель - вовлечение читателя в активный рецептивный диалог сопереживания - сотворчества - понимания.

Художественную стратегию общения с читателем использует и издатель, которого М.Н. Дарвин определил как «особого творческого субъекта, автора этой (журнальной. $-E . T$.) формы». И далее отметил: «Творческая роль автора журнала может быть сведена к созданию особой целостности формы как соединения разнородных текстов художественного и нехудожественного значений» [5. С. 277].

Художественная коммуникативная стратегия издателя реализуется в отборе, способах и последовательности представлении художественных произведений, вошедших в журнал, с расчетом их определенного восприятия. Преследуя цель в первую очередь эстетического развития ребенка, отбирая качественные произведения известных авторов из мировой художественной литературы, В.Н. Майков проектирует образ идеального читателя, не просто умеющего читать, но и владеющего «кодами» литературного произведения. Такого идеального читателя предстояло взрастить в рамках журнального метатекста. «Это означало, говоря словами В.С. Киселева, что в рамках метатекста, двигаясь от произведения к произведению, он расширял кругозор и усваивал новые способы ориентации, итогом же становилось превращение субъекта... в универсальную личность» [6. С. 25]. Это ориентация издателя придавала читателю внебытовой статус, делая его участником художественной реальности.

Однако преображение читателя-ребенка было возможно только путем постепенного восхождения. Детский журнал как «многоязычное» издание учитывал разный уровень интересов, компетентности, культуры, возраста (детский и юношеский) читателя, а потому издателю было важно выстроить общение с ним так, чтобы не отпугнуть от чтения, затем вовлечь в этот процесс, а далее сделать его участником активного рецептивного диалога. По сути, издательская художественная коммуникативная стратегия имела четкую направленность от читателя «наивного» к читателю рецептивному под руководством взрослого читателя-наставника.

Такая издательско-авторская позиция обнаруживается, прежде всего, в тех материалах, в нарративную структуру которых встраивается повествовательная ситуация с участием взрослого и ребенка. Такое художественное произведение появляется буквально в каждом 
номере «Подснежника», причем от номера к номеру усложняется коммуникативная модель: от авторитарных форм, где ребенок выступал в роли ведомого, к более свободным, предполагающим непрямые способы влияния, эстетическое воздействие.

В журнальном комплекте за первый 1958 г. отдельного внимания заслуживают произведения, части которых построены в форме беседы взрослого с ребенком, старшего с младшими. Известно, такие жанры, как беседа, наставление, поучение, были традиционны для детской литературы с момента ее зарождения, но критикой и педагогикой 1860-х гг. они были признаны архаичными в силу открытой назидательности, а потому нерекомендуемыми для детских изданий и писателей. Однако эти жанры были хорошо знакомы юному читателю из-за их распространенности в детской литературе первой половины XIX в. В.Н. Майков интуитивно почувствовал, что при первом знакомстве с изданием читатель будет искать в нем то, что ему ближе, а потому помещал в каждый номер журнала художественные произведения со встроенным знакомым жанровым механизмом.

Жанровая модель беседы-наставления выступала в своем привычном виде, выполняя традиционные функции: задавала программу прочтения, знакомила с тематикой художественного повествования, выводила к морали. Как правило, такие риторические зачины принадлежали повествователю или персонифицированному рассказчику, повествовательно-назидательная манера которого объединяла композиционные, достаточно самостоятельные части произведения: вводную, риторическую и основную, художественную. Роль повествователя сводится к прямому воздействию на читающего, и тот и другой оказываются за рамками художественного мира произведения.

В № 1 за 1858 г. издатель помещает рассказ В.И. Водовозова «Анализ», построенный по такому принципу. В первой части от лица повествователя вводится небольшой сюжет о неком Авдее Михайловиче, который использовал ученое слово «рационально» не по назначению и оттого был смешон. Далее дается установка на сам рассказ: если вы будете знать слово «анализ», то сможете уместно его употреблять. В «художественной» части рассказа раскрывается сюжет о мальчике Косте, который не знал значение данного слова. Однако риторическое слово повествователя обнаруживается и здесь за счет прямой апелляции к читателю: «вы верно, подобно моему 
знакомцу, не будете хвастать своею ученостью», «вы верно строго не осудите малютку», «представьте досаду, горесть, беспокойство Коли» и пр. Таким образом авторитарная позиция повествователя диктует восприятие текста ребенком. В составе журнального целого такую же позицию занимает издатель: в журнал входят две русские народные сказки, обработанные М. Михайловым, с очевидной моралью в финале (сказка «Три зятя» учит не завидовать, жить своей жизнью, «Кот и петушок» - быть послушным), поучительный рассказ «Машенька» В. Водовозова. Итак, художественная коммуникативная стратегия издателя в первых номерах «Подснежника» предполагала диалог-согласие автора журнала - авторов произведений читателя.

Постепенно журнал наряду с риторически-назидательными рассказами вводятся произведения, рассчитанные на более высокий уровень читательского восприятия, причем от номера к номеру их становится больше. Например, рядом с русскими сказками, дидактическим рассказом Водовозова, очерком о Преподобном Феодосии Печерском Л.Н. Каймова, написанным по канонам жанра жития, в № 2 за 1858 г. Майков помещает произведение И.А. Гончарова «Два случая из морской жизни». Повествование здесь строится в виде привычной юному читателю беседы взрослого путешественника со слушающими детьми. Но риторическое слово рассказчика уступает место художественному. Читатель вовлекается в художественный мир произведения, занимая точку зрения персонажей, его образ встраивается в коммуникативную систему рассказа. Так, Майков задает читателю более сложный художественный код прочтения, наделяет определенной степенью свободы интерпретации и подготавливает к переходу на новый уровень читательской практики.

Этот переход осуществляется в журнальном метатексте второго года выпуска «Подснежника». Номера 1859 г. объединяет произведение Н. Готорна «Собрание чудес, повести для детей, заимствованные из мифологии», которое можно назвать программным как для каждого номера, так и для годового комплекта в целом: каждый номер открывается повестью из готорновского цикла. Выбор данного произведения в качестве центрального может быть обусловлен несколькими причинами, одна из которых - соответствие сложной субъектной организации цикла коммуникативным задачам издателя. 
Каждая мифологическая повесть имеет художественную раму со своим сюжетом, поданным от лица безличного повествователя (встреча и подготовка беседы в начале и обсуждение услышанного в конце), системой героев (это подросток, юный наставник, ученый муж Евстафий Брайт, «заслуживший между детьми славу рассказчика волшебных сказок», и его слушатели - маленькие дети), со своей пространственно-временной организацией (идиллический хронотоп). Самостоятельность рамочного текста в составе отдельной повести подчеркивает и индивидуальный заголовок к нему, имеющий пространственное обозначение: «На крыльце Тенгвульда», «На берегу ручья», «На склоне холма». Художественно-мифологическое повествование о голове Горгоны, золотом осязании и прочем вложено в уста «любезного братца», «милого кузена» Брайта и адресовано слушающим.

Н. Готорн объединяет миниатюры, формируя художественную жанровую структуру «истории в истории», где повествователь, рассказчик и слушатели становятся художественными образами. Помещая такое произведение в свой журнал, Майков окончательно отходит от риторических форм общения с читателем-ребенком, размыкая текстовые границы и на какое-то время погружая субъекта в иное коммуникативное измерение, понять которое можно, владея определенными художественными кодами. В составе журнального целого реализации такой коммуникативной стратегии издателя способствовал и журнальный художественный контекст: это отрывки из романа Бичер-Стоу (1859. № 2, 3), Ферри (1859. № 7), Шарля Дели (1859. № 7) и др.

Начиная с третьего года существования журнала общение с читателем-ребенком теряет любые риторические формы, целиком переносится в мир художественного произведения и выполняет художественно-эстетические функции. Издатель продолжает помещать в журнал произведения, воспроизводящие ситуацию общения взрослого с ребенком, но теперь и тот и другой являются героями художественного повествования. Таков рассказчик в повестях «Утиное болото» (перевод с фр.) (1860. № 2), «Дедушка и внучка» (составлено по роману Ч. Диккенса «Лавка древностей») (1861. № 1) и др. В процессе их прочтения читатель вынужден соотносить свои ощущения с чувствами и ощущениями персонажей, переносить на себя их эмоции, проходить череду событий, обретая новое для себя. 
Постепенное приобщение читателя к таким произведениям с позиции издателя выдвигало на первый план культуртрегерскую функцию журнала, в чем состояла задача художественной коммуникативной стратегии Майкова.

Таким образом, использование двух различных по своим функциям, задачам, адресатам издательских коммуникативных стратегий позволило В.Н. Майкову сделать свой журнал «Подснежник», с одной стороны, коммерчески успешным, популярным, заслужившим положительные отклики взрослой аудитории: подписчиков, критиков, педагогов, журналистов, а с другой стороны, интересным и неназидательно полезным для детского читателя, разного по культурному опыту, социальной принадлежности, читательской компетентности, имеющего возможность «вырасти» в метатекстовом пространстве журнала. Единство этих стратегий, на наш взгляд, и определяет новизну данного издания.

\section{Лumepamypa}

1. Колесова Л.Н. Детские журналы России (1785-1917): учеб.-метод. комплект. Петрозаводск: Изд-во ПетрГУ, 2014. 260 с.

2. Мордовченко Н.И. Журналистика двадцатых - тридцатых годов [XIX века] // История русской литературы: в 10 т. / АН СССР. Ин-т рус. лит. (Пушкинский Дом). М.; Л.: Изд-во АН СССР, 1953. Т 6: Литература 1820-1830-х годов. С. 579-610 // ФЭБ. Режим доступа: http://feb-web.ru/feb/irl/il0/il6/il6-579-.htm

3. Володина Н.В. Майковы; отв ред. В.А. Котельников. СПб.: Наука, 2003. 340 с. (Преданья русского семейства).

4. Подснежник: журнал для детского и юношеского возрастов / изд. В.Н. Майков. Санкт-Петербург. 1858-1862.

5. Дарвин М.Н. Циклизация в творчестве Пушкина: Опыт изучения поэтики конвергентного сознания / М.Н. Дарвин, В.И. Тюпа; Рос. акад. наук. Сиб. отд-ние. Ин-т филологии. Новосибирск: Наука, 2001. 292 с.

6. Киселев В.С. Читатель в метатекстовой коммуникации // Статьи по теории и истории метатекста (на материале русской прозы конца XVIII - первой трети ХІХ века). Томск, 2004. С. 23-28.

COMMUNICATION STRATEGIES OF THE PUBLISHER IN V. MAYKOV'S PODSNEZHNIK, A MAGAZINE "FOR CHILDREN'S AND ADOLESCENTS' READING" (1858-1862).

Text. Book. Publishing, 2015, 2 (9), pp. 25-38. DOI: 10.17223/23062061/9/2

Tulyakova Elena I. Tomsk State University (Tomsk, Russian Federation). E-mail: purple15@rambler.ru

Keywords: children's magazine; communication strategies; reader, metatext. 
The journalism of the $1850 \mathrm{~s}-1860$ s referred to the 19 th century as to the time of professional children's magazine development. At this time, the number of children's magazines increases, they show differentiation and develop typical features. A magazine of the "new type" that laid the foundation for the professional children's periodical was Podsnezhnik ("Snowdrop") (1858-1862). Its concept and place in the children's journalism was largely determined by the figure of its publisher, Vladimir Nikolaevich Maikov (18261885). Knowing well the literary and journalistic milieu of his time, he organized a children's magazine as a successful business enterprise using pragmatic and artistic communication strategies.

The pragmatic strategy of the publisher was connected with the expansion of readership, distribution territory, price reduction, marketing moves (a gift for a subscription, advertising of books and bookshops), and so on. A pragmatic approach also determined the publishing paratext of the magazine. It primarily focused on the adult reader-buyer with literary and pedagogical expertise, familiar with the book culture of the, and concerned with the aesthetic and intellectual upbringing of the child. The publishing paratext was organized in order to convince an adult mentor in the authority of the magazine and in the usefulness of its purchasing for the young reader. This, according to the publisher, was evidenced by the censorship permission, pedagogical materials (instructive pedagogical articles, educational and aesthetic program of the magazine, educational notes of the editor to the popular scientific articles), the high quality of the published works of art (selection of authors the adult reader knew, selection of the best works written especially for children, part of children's reading, focus on the popular genres adult literature: a lyric poem, novel, short story), the visual appeal of the magazine, its usability (the rigor and clarity of design, selection of illustrations, etc.).

The publisher had a different communication strategy for the child-reader, it can be called aesthetic, or artistic. It is related to the selection, method and sequence of materials placement in the metatext unity of the magazine. The strategy is designed for the upbringing of ideal readers from their introduction to reading to involvement in this process and participation in the receptive dialogue under the leadership of the adult reader-mentor. This publisher and author's position reveals primarily in the materials whose narrative structure integrates a narrative situation involving an adult and a child. It is no coincidence that materials with forms of conversation appear in virtually every issue of Podsnezhnik; and with every issue the communicative model becomes more complicated: from authoritarian forms where the child was guided to free ones, implying indirect influence, an aesthetic impact. It is the unity of the two opposing communication publishing strategies that determines the novelty of the children's magazine Podsnezhnik.

\section{References}

1. Kolesova, L.N. (2014) Detskie zhurnaly Rossii (1785-1917) [Children's magazines in Russia (1785-1917)]. Petrozavodsk: Petrozavodsk State University.

2. Mordovchenko, N.I. (1953) Zhurnalistika dvadtsatykh — tridtsatykh godov [XIX veka] [Journalism of the twenties - thirties [19th century]]. In: Meilakh, B.S. (ed.) Istoriya russkoy literatury: $v 10 \mathrm{t}$. [The History of Russian Literature: In 10 Vols.]. Vol. 6. Moscow; Leningrad: USSR AS. pp. 579-610. [Online] Available from: http://febweb.ru/feb/irl/i10/il6/il6-579-.htm.

3. Volodina, N.V. (2003) Maykovy [The Maykovs]. St. Petersburg: Nauka. 
4. Podsnezhnik [Snowdrop]. A Magazine for Children and Youth. St. Petersburg. 1858-1862.

5. Darwin, M.N. \& Tyupa, V.I. (2001) Tsiklizatsiya v tvorchestve Pushkina: Opyt izucheniya poetiki konvergentnogo soznaniya [Cycles in Pushkin's Works: On Studying the Poetics of Convergent Consciousness]. Novosibirsk: Nauka.

6. Kiselev, V.S. (2004) Stat'i po teorii i istorii metateksta (na materiale russkoy prozy kontsa XVIII - pervoy treti XIX veka) [Articles on the theory and history of the metatext (based on the Russian prose of the late 18th - early 19th centuries)]. Tomsk: Tomsk State University. pp. 23-28. 